\title{
Clinical significance of the FIB-4 index for non-B non-C hepatocellular carcinoma treated with surgical resection
}

\author{
HIROKI NISHIKAWA $^{1}$, YUKIO OSAKI ${ }^{1}$, HIDEYUKI KOMEKADO ${ }^{1}$, AZUSA SAKAMOTO ${ }^{1}$, \\ SUMIO SAITO $^{1}$, NORIHIRO NISHIJIMA ${ }^{1}$, AKIHIRO NASU ${ }^{1}$, AKIRA ARIMOTO $^{2}$, \\ RYUICHI KITA $^{1}$ and TORU KIMURA ${ }^{1}$
}

\author{
Departments of ${ }^{1}$ Gastroenterology and Hepatology, and ${ }^{2}$ Surgery,
}

Osaka Red Cross Hospital, Tennoji-ku, Osaka 543-0027, Japan

Received August 18, 2014; Accepted October 7, 2014

DOI: $10.3892 /$ or.2014.3573

\begin{abstract}
The aims of the present study were to examine the relationship between the preoperative FIB-4 index and background liver fibrosis in non-tumor parts obtained from surgical specimens and to investigate whether the FIB-4 index can be a useful predictor for non-B non-C hepatocellular carcinoma (NBNC-HCC) patients treated with surgical resection (SR). A total of 118 patients with NBNC-HCC treated with SR with curative intent were analyzed. Receiver operating characteristic (ROC) curve analysis was performed for calculating the area under the ROC (AUROC) for the FIB-4 index, aspartate aminotransferase (AST) to platelet ratio index, AST to alanine aminotransferase ratio, serum albumin, total bilirubin and platelet count for cirrhosis. We also examined predictors linked to overall survival (OS) and recurrence-free survival (RFS) after SR. The mean patient age was $68.9 \pm 9.0$ years ( 93 males and 25 females) with a median observation period of 3.2 years. In extracted surgical specimens, background liver cirrhosis (F4) was observed in 39 patients (33.1\%). The mean maximum tumor size was $5.7 \pm 3.2 \mathrm{~cm}$. The mean body mass index was $24.3 \pm 3.9 \mathrm{~kg} / \mathrm{m}^{2}$. The FIB-4 index yielded the highest AUROC for cirrhosis with a level of 0.887 at an optimal cut-off value of 2.97 (sensitivity, 92.3; specificity, 69.6\%). In the multivariate analysis, serum $\alpha$-fetoprotein $>40 \mathrm{ng} / \mathrm{ml}(\mathrm{P}=0.026)$ was the only significant independent predictor linked to OS, while tumor number $(\mathrm{P}=0.002)$ and FIB-4 index $>2.97(\mathrm{P}=0.044)$ were significant factors linked to RFS. In conclusion, preoperative FIB-4 index can be a useful predictor for NBNC-HCC patients who undergo SR.
\end{abstract}

Correspondence to: Dr Hiroki Nishikawa, Department of Gastroenterology and Hepatology, Osaka Red Cross Hospital, 5-30 Fudegasaki-cho, Tennoji-ku, Osaka 543-0027, Japan

E-mail: h-nishikawa@osaka-med.jrc.or.jp

Key words: non-B non-C hepatocellular carcinoma, liver fibrosis, FIB-4 index, overall survival, recurrence-free survival

\section{Introduction}

Hepatocellular carcinoma (HCC) is the fifth most common cancer in the world and the third most common cause of cancerrelated death (1-3). Although most cases of this malignancy are associated with viral infections such as hepatitis B virus (HBV) and hepatitis $\mathrm{C}$ virus (HCV) infections, a substantial proportion of HCC patients are negative for markers of HBV surface antigen (HBsAg) and HCV antibody (HCVAb) [non-B non-C HCC (NBNC-HCC)]. The frequency of NBNC-HCC has been reported to range from 5 to $15 \%$, and the number of NBNC-HCC patients in Japan has recently been gradually increasing (4-7). It is noteworthy that the proportion of NBNC-HCC patients was $230 \%$ in 2011, 2012 and 2013 in our hospital (1).

Curative therapies for HCC consist of liver transplantation, surgical resection (SR) and radiofrequency ablation (RFA) (1-7). The clinical outcome of HCC patients undergoing these therapies has improved substantially in recent years due to their advances. However, HCC often recurs even after curative therapies, leading to high mortality. Recurrence only occurs at intrahepatic sites in $68-96 \%$ of patients $(1,8-10)$. Hence, the identification of predictive factors and effective management of $\mathrm{HCC}$ recurrence are essential for improving survival, even after curative treatment.

Recently, several noninvasive tools have been introduced to evaluate the degree of hepatic fibrosis in patients with chronic liver disease; these include serum markers such as aspartate aminotransferase to platelet ratio index (APRI), FIB-4 index, aspartate aminotransferase (AST) to alanine aminotransferase (ALT) ratio or modalities such as acoustic radiation force impulse, transient elastography and magnetic resonance elastography (11-18). Serum markers and developed scores are of rising significance in noninvasive diagnosis of liver fibrosis owing to the easy availability in field practice. Among these tools, the FIB-4 index is a simple formula used for predicting liver fibrosis based on standard biochemical values (platelet count, AST and ALT) and age, and is demonstrated to be highly helpful for predicting advanced liver fibrosis (19-22). However, this test has seldom been applied for the evaluation 
of liver function prior to SR and for prediction of clinical outcomes for NBNC-HCC patients who undergo SR, although there are several reports regarding the clinical significance of preoperative APRI on survival in HBV-related HCC patients treated with SR $(23,24)$.

The aims of the present study were to examine the relationship between preoperative FIB-4 index and background liver fibrosis in non-tumor parts obtained from extracted surgical specimens and to investigate whether the preoperative FIB-4 index can be a useful predictor for NBNC-HCC patients treated with SR.

\section{Patients and methods}

Patients. A total of 128 treatment-naïve NBNC-HCC patients received SR at our institution between June 2004 and June 2014 with curative intent. Curative surgery was defined as resection of all tumors detectable using imaging modalities. NBNC-HCC was defined as HCC negative for both $\mathrm{HBsAg}$ and HCVAb. Patients with severe alcoholic cirrhosis $(n=7)$, a patient with autoimmune hepatitis $(n=1)$ and patients with primary biliary cirrhosis $(n=2)$ were excluded from the present study. A total of 118 NBNC-HCC patients were thus analyzed in the present study. A diagnosis of diabetes mellitus (DM) was based on past medical history or 75-g oral glucose tolerance test results (25). We examined predictive factors associated with overall survival (OS) and recurrence-free survival (RFS) in univariate and multivariate analyses.

Written informed consent was obtained from all patients prior to SR, and the study protocol complied with all of the provisions of the Declaration of Helsinki. The present study was approved by the Ethics Committee of Osaka Red Cross Hospital, Japan. The present study comprised a retrospective analysis of patient records registered in our database, and all treatments were conducted in an open-label manner.

Calculated scores. The APRI score was calculated using Wai's formula: (AST/upper limit of normal)/platelet count (expressed as platelets $\left.\times 10^{9} / 1\right) \times 100(26)$. The FIB-4 score was calculated using Sterling's formula as: [age (years) x AST (IU/l)/platelet count $\left.\left(\times 10^{9} / 1\right) \times \operatorname{ALT}^{1 / 2}(\mathrm{IU} / \mathrm{l})\right](27)$.

HCC diagnosis. HCC was diagnosed using abdominal ultrasound and dynamic CT scans (hyperattenuation during the arterial phase in all or some part of the tumor and hypoattenuation in the portal-venous phase) and/or magnetic resonance imaging (MRI), based mainly on the recommendations of the American Association for the Study of Liver Diseases (28). Arterial- and portal-phase dynamic CT images were obtained at $\sim 30$ and $120 \mathrm{sec}$, respectively, after the injection of the contrast material. HCC stage was determined using the Liver Cancer Study Group of Japan staging system (29). All HCC was confirmed pathologically except for two cases with complete necrosis due to preoperative transcatheter arterial chemoembolization (TACE).

Hepatectomy and surgical procedure. All surgical procedures were performed by one of four surgeons with at least 10 years experience of SR. Anatomical SR was defined as a resection in which tumors were completely removed anatomically on the basis of Couinaud's classification (segmentectomy, sectionectomy and hemihepatectomy, or extended hemihepatectomy). Non-anatomical partial SR was carried out as a limited resection or tumor enucleation. Anatomical SR was performed in 68 patients $(57.6 \%)$ and non-anatomical SR was performed in 50 patients $(42.4 \%)$ in the present study. Conventional open hepatectomy was performed in 95 patients (80.5\%), and laparoscopic hepatectomy was performed in 23 patients $(19.5 \%)$ in the present study.

Histological evaluation of the extracted liver specimens. All extracted liver specimens were reviewed by a single pathologist in our hospital. Background liver fibrosis was staged as F0 to F4: F0, no fibrosis; F1, portal fibrosis without septa; F2, portal fibrosis and a few septa; F3, numerous septa without cirrhosis; and F4, cirrhosis. The degree of differentiation of $\mathrm{HCC}$ in each resected specimen was determined as welldifferentiated HCC, moderately differentiated HCC, poorly differentiated HCC or combined type of HCC and cholangiocellular carcinoma (CCC) (30).

Follow-up. Follow-up after each therapy consisted of periodic blood tests and monitoring of tumor markers, including $\alpha$-fetoprotein (AFP) and des- $\gamma$-carboxy prothrombin (DCP), using chemiluminescent enzyme immunoassays (Lumipulse PIVKA-II Eisai; Eisai, Tokyo, Japan). Dynamic CT scans and/or MRI were obtained every 2-4 months after each therapy. Chest $\mathrm{CT}$, whole abdominal $\mathrm{CT}$, brain MRI, and bone scintigraphy were performed when extrahepatic HCC recurrence was suspected. When HCC recurred, the most appropriate therapy for HCC recurrence was performed considering tumor status, liver function or performance status of the patients.

Statistical analysis. Data were analyzed using univariate and multivariate analyses. Continuous variables were compared between groups by the Mann-Whitney U test. Receiver operating characteristic (ROC) curve analysis was performed for calculating the area under the ROC (AUROC) for the FIB-4 index, APRI, AST to ALT ratio, serum albumin, total bilirubin and platelet count and selecting the optimal cut-off value that maximized the sum of sensitivity and specificity for liver cirrhosis (F4). Time to recurrence was defined as the interval between initial therapy and first confirmed recurrence. For analysis of RFS, follow-up ended at the time of first recurrence; other patients were censored at their last follow-up visit or the time of death from any cause without recurrence. For analysis of OS, follow-up ended at the time of death from any cause, and the remaining patients were censored at the last follow-up visit. The cumulative OS and RFS rates were calculated using the Kaplan-Meier method, and tested using the log-rank test. Factors with a P-value $<0.05$ in univariate analysis were subjected to multivariate analysis using the Cox proportional hazards model. These statistical methods were used to estimate the interval from initial treatment. Data were analyzed using SPSS software (SPSS, Inc., Chicago, IL, USA) for Microsoft Windows. Data are expressed as means \pm standard deviation (SD). Values of $\mathrm{P}<0.05$ were considered to indicate statistically significant differences. 
Table I. Baseline characteristics of the patients with non-B and non- $\mathrm{C}$ hepatocellular carcinoma $(\mathrm{n}=118)$.

\begin{tabular}{|c|c|}
\hline Variables & Data $(\mathrm{N}=118)$ \\
\hline Age (years) & $68.9 \pm 9.0$ \\
\hline Gender, male/female & $93 / 25$ \\
\hline Body mass index $\left(\mathrm{kg} / \mathrm{m}^{2}\right)$ & $24.3 \pm 3.9$ \\
\hline Diabetes mellitus, yes/no & $53 / 65$ \\
\hline HCC stage, I/II/III/IV & $4 / 74 / 33 / 7$ \\
\hline Maximum tumor size $(\mathrm{cm})$ & $5.7 \pm 3.2$ \\
\hline Tumor number, single/multiple & $75 / 43$ \\
\hline AST (IU/l) & $43.4 \pm 26.0$ \\
\hline ALT (IU/l) & $37.8 \pm 29.4$ \\
\hline $\operatorname{ALP}(\mathrm{IU} / \mathrm{l})$ & $343.8 \pm 186.8$ \\
\hline GGT (IU/l) & $158.8 \pm 170.6$ \\
\hline Serum albumin (g/dl) & $4.0 \pm 0.5$ \\
\hline Total bilirubin (mg/dl) & $0.8 \pm 0.4$ \\
\hline Prothrombin time $(\%)^{\mathrm{a}}$ & $92.5 \pm 18.7$ \\
\hline Platelets $\left(\mathrm{x} 10^{4} / \mathrm{mm}^{3}\right)$ & $17.0 \pm 8.1$ \\
\hline $\operatorname{AFP}(\mathrm{ng} / \mathrm{ml})$ & $1,713 \pm 11,917$ \\
\hline $\mathrm{DCP}(\mathrm{mAU} / \mathrm{ml})^{\mathrm{b}}$ & $8,629 \pm 48,077$ \\
\hline \multicolumn{2}{|l|}{$\begin{array}{l}\text { Histological findings } \\
\text { (extracted surgical specimen) }\end{array}$} \\
\hline Background liver fibrosis, F4/3/2/1/0 & $39 / 20 / 22 / 14 / 23$ \\
\hline $\begin{array}{l}\text { Tumor differentiation, } \\
\text { well/moderate/poor/combined/necrosis }\end{array}$ & $11 / 69 / 33 / 3 / 2$ \\
\hline \multicolumn{2}{|c|}{$\begin{array}{l}\text { Data are expressed as number or mean } \pm \text { standard deviation. HCC, } \\
\text { hepatocellular carcinoma; AST, aspartate aminotransferase; ALT, ala- } \\
\text { nine aminotransferase; ALP, alkaline phosphatase; GGT, } \gamma \text {-glutamyl } \\
\text { transpeptidase; AFP, } \alpha \text {-fetoprotein; DCP, des- } \gamma \text {-carboxy prothrombin. } \\
{ }^{a} \text { Missing data, } n=2 ; \text { bissing data, } n=2 \text {. Combined means combined } \\
\text { type of HCC and cholangiocellular carcinoma. Necrosis means com- } \\
\text { plete necrosis. }\end{array}$} \\
\hline
\end{tabular}

\section{Results}

Baseline characteristics. The baseline characteristics of the analyzed patients $(\mathrm{n}=118)$ are shown in Table I. The mean age was $68.9 \pm 9.0$ years. The median observation period was 3.2 years (range, 0.1-10.1 years). There were 93 males and 25 females. The mean maximum tumor size was $5.7 \pm 3.2 \mathrm{~cm}$. The mean body mass index (BMI) was $24.3 \pm 3.9 \mathrm{~kg} / \mathrm{m}^{2}$. As for the histological findings, in terms of the degree of liver fibrosis in the non-tumor portion, F4 was observed in 39 patients, $\mathrm{F} 3$ in 20, F2 in 22, F1 in 14 and F0 in 23, whereas in terms of HCC histology, well-differentiated HCC was observed in 11 patients, moderately differentiated $\mathrm{HCC}$ in 69 , poorly differentiated HCC in 33, combined type of HCC and CCC in 3 and complete necrosis due to preoperative TACE in 2 patients.

Comparison of the area under receiver operating curves for serum markers for liver cirrhosis. We evaluated the correlation between serum markers including FIB-4 index, APRI, AST to ALT ratio, platelet count, serum albumin and total bilirubin

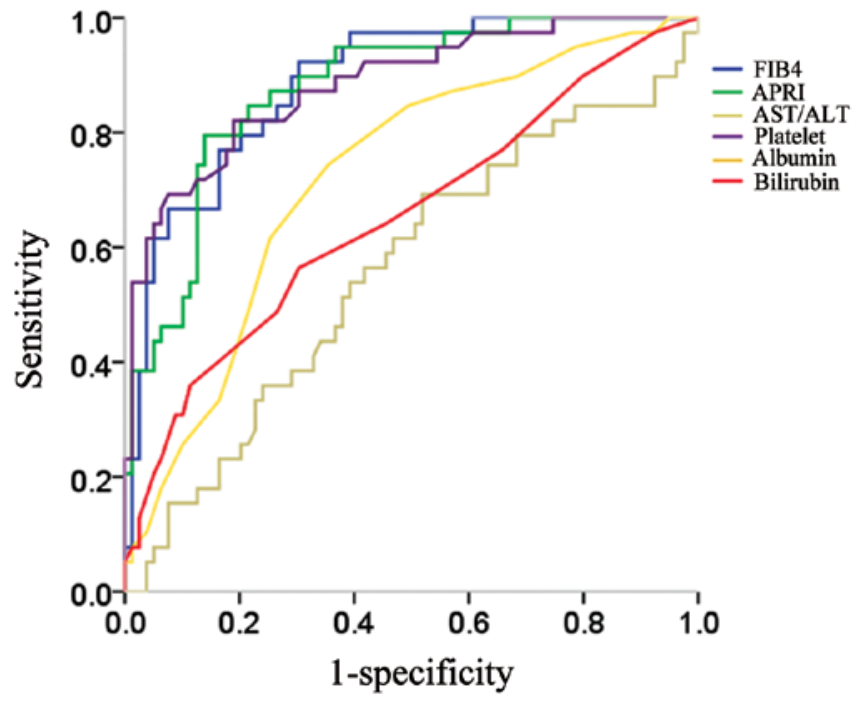

Figure 1. Correlation between serum markers including FIB-4 index, AST to platelet ratio index (APRI), AST to ALT ratio, platelet count, serum albumin and total bilirubin and liver cirrhosis (F4). FIB-4 index yielded the highest AUROC with a level of 0.887 at an optimal cut-off value of 2.97 (sensitivity, 92.3\%; specificity, $69.6 \%$ ). AST, aspartate aminotransferase; ALT, alanine aminotransferase; AUROC, area under the ROC; ROC, receiver operating characteristic.

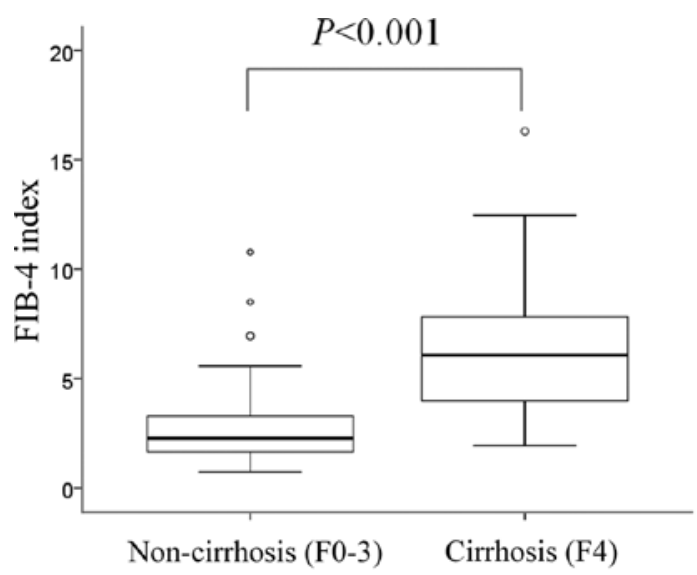

Mann-Whitney $U$ test

Figure 2. Box plots of the FIB-4 index between patients with non-cirrhosis (F0-3) and those with cirrhosis (F4). The FIB-4 index in patients with liver cirrhosis $(n=39)$ was significantly higher than that in those with non-liver cirrhosis $(\mathrm{n}=79)(\mathrm{P}<0.001$, Mann-Whitney U test).

and liver cirrhosis (F4). Receiver operating curves of the serum markers used for predicting liver cirrhosis are demonstrated in Fig. 1. FIB-4 index, APRI and platelet count exhibited reliable discriminative ability for predicting liver cirrhosis. Among these, the FIB-4 index yielded the highest AUROC with a level of 0.887 at an optimal cut-off value of 2.97 (sensitivity, 92.3\%; specificity, 69.6\%) (Table II). The FIB-4 index in patients with liver cirrhosis $(\mathrm{F} 4, \mathrm{n}=39)$ was significantly higher than that in the patients with non-liver cirrhosis $(\mathrm{F} 0-3, \mathrm{n}=79)(\mathrm{P}<0.001$, Mann-Whitney U test) (Fig. 2).

Cumulative OS and RFS rates for all patients. For all patients $(\mathrm{n}=118)$, the 1-, 3- and 5-year cumulative OS rates were 92.0, 
Table II. Comparison of the area under the receiver operating curves (AUROCs) for FIB-4 index, APRI, AST to ALT ratio, platelet count, serum albumin and total bilirubin for liver cirrhosis.

\begin{tabular}{|c|c|c|c|c|}
\hline & AUROC & $95 \% \mathrm{CI}$ & Standard error & P-value \\
\hline FIB-4 index & 0.887 & $0.828-0.947$ & 0.030 & $<0.001$ \\
\hline APRI & 0.877 & $0.814-0.941$ & 0.032 & $<0.001$ \\
\hline AST to ALT ratio & 0.559 & $0.446-0.671$ & 0.057 & 0.302 \\
\hline Platelet count $\left(/ \mathrm{mm}^{3}\right)$ & 0.883 & $0.818-0.949$ & 0.034 & $<0.001$ \\
\hline Serum albumin $(\mathrm{g} / \mathrm{dl})$ & 0.724 & $0.629-0.820$ & 0.049 & $<0.001$ \\
\hline Total bilirubin (mg/dl) & 0.652 & $0.543-0.761$ & 0.056 & 0.007 \\
\hline
\end{tabular}

APRI, AST to platelet ratio index; AST, aspartate aminotransferase; ALT, alanine aminotransferase; CI, confidence interval; AUROCs, area under the ROC; ROC, receiver operating characteristic.

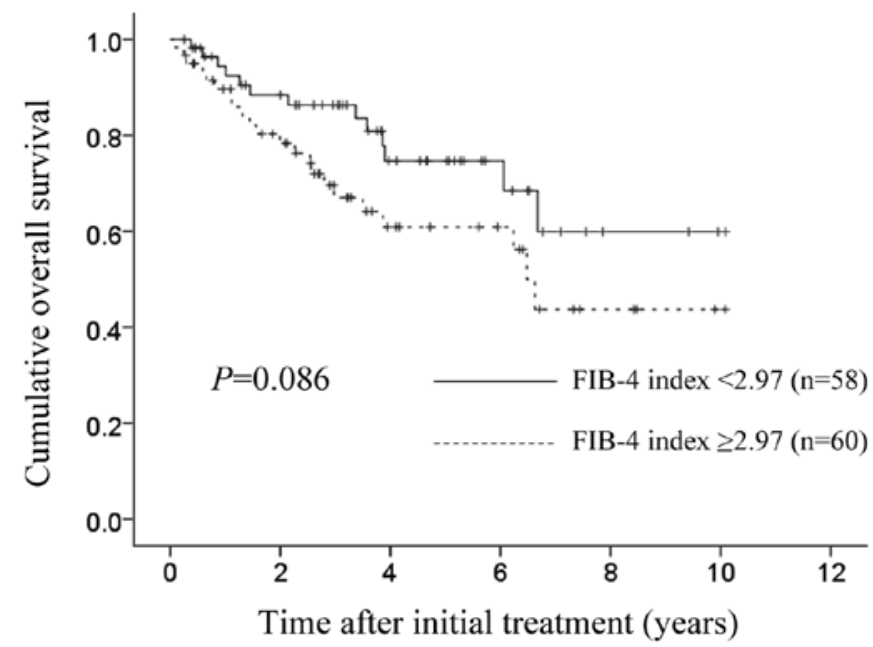

Figure 3. Cumulative overall survival (OS) rates according to FIB-4 index The 1-, 3- and 5-year cumulative OS rates in patients with FIB-4 index >2.97 $(n=60)$ were $89.7,67.0$ and $60.9 \%$, respectively, and the corresponding cumulative OS rate in patients with FIB-4 index $<2.97(\mathrm{n}=58)$ were $94.4,86.3$ and $74.7 \%$, respectively $(\mathrm{P}=0.086)$.

76.6 and $67.6 \%$, respectively. The corresponding RFS rates were $71.9,37.8$ and $30.5 \%$, respectively.

Cumulative $O S$ and RFS rates according to FIB-4 index. The 1-, 3- and 5-year cumulative OS rates in patients with FIB-4 index $>2.97$ (optimal cut-off value) $(n=60)$ were 89.7, 67.0 and $60.9 \%$, respectively, and the corresponding cumulative OS rates in patients with FIB-4 index <2.97 ( $\mathrm{n}=58)$ were 94.4, 86.3 and $74.7 \%$, respectively $(\mathrm{P}=0.086$ ) (Fig. 3). The 1-, 3- and 5 -year cumulative RFS rates in patients with FIB-4 index $>2.97$ were $66.6,29.8$ and $20.2 \%$, respectively, and the corresponding cumulative RFS rates in patients with FIB-4 index $<2.97$ were $75.2,45.8$ and $40.1 \%$, respectively $(\mathrm{P}=0.014)$ (Fig. 4).

Univariate and multivariate analyses of factors contributing to $O S$. Univariate analysis identified the following factors as significantly associated with OS for all cases $(n=118)$ : tumor number (single or multiple) $(\mathrm{P}=0.006)$; alkaline phosphatase $(\mathrm{ALP})>300 \mathrm{IU} / 1(\mathrm{P}=0.037)$; serum albumin $>4.0 \mathrm{~g} / \mathrm{dl}$

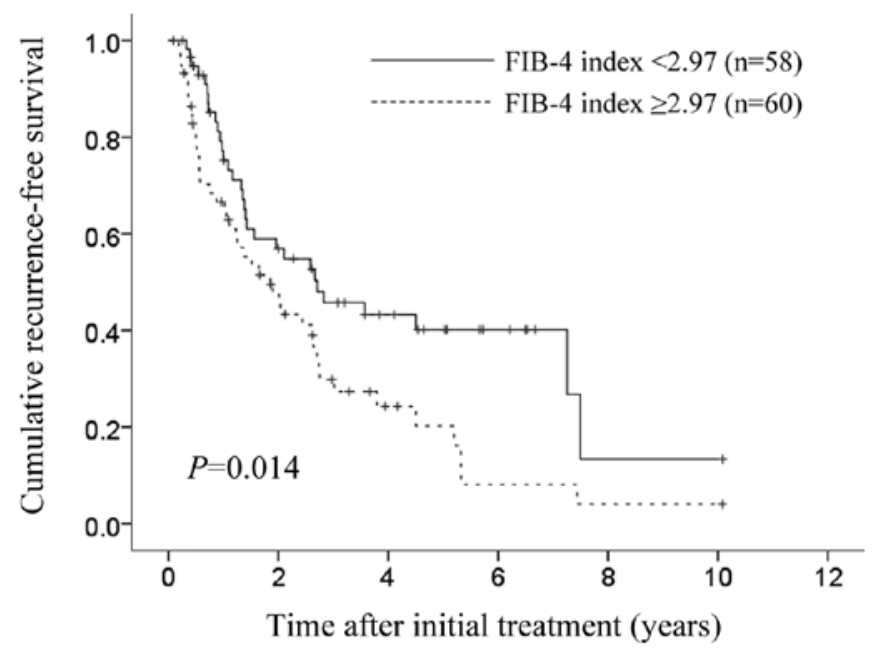

Figure 4. Cumulative recurrence-free survival (RFS) rates according to FIB-4 index. The 1-, 3- and 5-year cumulative RFS rates in patients with FIB-4 index $>2.97$ were $66.6,29.8$ and $20.2 \%$, respectively, and the corresponding cumulative RFS rate in patients with FIB-4 index $<2.97$ were 75.2 , 45.8 and $40.1 \%$, respectively $(\mathrm{P}=0.014)$.

$(\mathrm{P}=0.010)$; and AFP $>40 \mathrm{ng} / \mathrm{ml}(\mathrm{P}=0.048)$ (Table III). The hazard ratios (HRs) and $95 \%$ confidence intervals (CIs) calculated using multivariate analysis for the four factors with P-values of $<0.05$ in univariate analysis are detailed in Table III. Only the AFP value was found to be a significant predictor linked to $\mathrm{OS}$ in multivariate analysis $(\mathrm{P}=0.026)$.

Univariate and multivariate analyses of factors contributing to RFS. Univariate analysis identified the following factors as significantly associated with RFS for all cases $(n=118)$ : tumor number (single or multiple) $(\mathrm{P}<0.001)$; presence of microscopic vascular invasion $(\mathrm{P}=0.024)$; ALP $>300 \mathrm{IU} / 1$ $(\mathrm{P}=0.002) ; \gamma$-glutamyl transpeptidase $(\mathrm{GGT})>100 \mathrm{IU} / 1$ $(\mathrm{P}=0.010)$; and FIB-4 index $>2.97(\mathrm{P}=0.014)$ (Table IV). The HRs and $95 \%$ CIs calculated using multivariate analysis for the five factors with $\mathrm{P}$-values of $<0.05$ in univariate analysis are detailed in Table IV. Tumor number $(\mathrm{P}=0.002)$ and FIB-4 index $(\mathrm{P}=0.044)$ were found to be significant prognostic factors linked to RFS. 
Table III. Univariate and multivariate analysis of factors contributing to overall survival.

\begin{tabular}{|c|c|c|c|c|}
\hline \multirow[b]{2}{*}{ Variables } & \multirow[b]{2}{*}{$\mathrm{n}$} & \multirow{2}{*}{$\begin{array}{l}\text { Univariate } \\
\text { analysis }\end{array}$} & \multicolumn{2}{|c|}{ Multivariate analysis } \\
\hline & & & Hazard ratio $(95 \% \mathrm{CI})$ & P-value ${ }^{a}$ \\
\hline Gender, male vs. female & $93 / 25$ & 0.330 & & \\
\hline Age (years), $>70$ vs. $\leq 70$ & $58 / 60$ & 0.802 & & \\
\hline Tumor number, single vs. multiple & $75 / 43$ & 0.006 & $0.544(0.271-1.092)$ & 0.087 \\
\hline Maximum tumor size $(\mathrm{cm}), \geq 4.5$ vs. $<4.5$ & $59 / 59$ & 0.386 & & \\
\hline Microscopic vascular invasion, yes vs. no & $52 / 66$ & 0.100 & & \\
\hline $\operatorname{AST}(\mathrm{IU} / \mathrm{l}), \geq 40$ vs. $<40$ & $53 / 65$ & 0.561 & & \\
\hline $\operatorname{ALT}(\mathrm{IU} / 1), \geq 40$ vs. $<40$ & $34 / 84$ & 0.196 & & \\
\hline $\operatorname{ALP}(\mathrm{IU} / 1), \geq 300$ vs. $<300$ & $56 / 62$ & 0.037 & $0.514(0.239-1.104)$ & 0.088 \\
\hline GGT (IU/l), $\geq 100$ vs. $<100$ & $58 / 60$ & 0.370 & & \\
\hline FIB-4 index $\geq 2.97$, yes vs. no & $60 / 58$ & 0.086 & & \\
\hline Serum albumin level $(\mathrm{g} / \mathrm{dl}), \geq 4.0$ vs. $<4.0$ & $74 / 44$ & 0.010 & $1.991(0.986-4.022)$ & 0.055 \\
\hline Total bilirubin $(\mathrm{mg} / \mathrm{dl}), \geq 1.0 \mathrm{vs} .<1.0$ & $23 / 95$ & 0.465 & & \\
\hline Platelet count $\left(\mathrm{x} 10^{4} / \mathrm{mm}^{3}\right), \geq 15$ vs. $<15$ & $64 / 54$ & 0.205 & & \\
\hline Prothrombin time $(\%), \geq 80$ vs. $<80^{\mathrm{b}}$ & $98 / 18$ & 0.051 & & \\
\hline Diabetes mellitus, yes vs. no & $53 / 65$ & 0.150 & & \\
\hline Body mass index $\left(\mathrm{kg} / \mathrm{m}^{2}\right), \geq 25 \mathrm{vs} .<25$ & $49 / 69$ & 0.322 & & \\
\hline $\operatorname{Serum~AFP~}(\mathrm{ng} / \mathrm{ml}), \geq 40$ vs. $<40$ & $31 / 87$ & 0.048 & $0.427(0.202-0.904)$ & 0.026 \\
\hline DCP $(\mathrm{mAU} / \mathrm{ml}), \geq 200 \mathrm{vs} .<200^{\mathrm{c}}$ & $61 / 55$ & 0.406 & & \\
\hline
\end{tabular}

CI, confidence interval; AST, aspartate aminotransferase; ALT, alanine aminotransferase; ALP, alkaline phosphatase; GGT, $\gamma$-glutamyl transpeptidase; AFP, $\alpha$-fetoprotein; DCP, des- $\gamma$-carboxy prothrombin. ${ }^{a}$ Cox proportional hazard model; ${ }^{b}$ missing data, $n=2$; ${ }^{c}$ missing data, $n=2$.

Table IV. Univariate and multivariate analysis of factors contributing to recurrence-free survival.

\begin{tabular}{|c|c|c|c|c|}
\hline \multirow[b]{2}{*}{ Variables } & \multirow[b]{2}{*}{$\mathrm{n}$} & \multirow{2}{*}{$\begin{array}{c}\text { Univariate } \\
\text { analysis }\end{array}$} & \multicolumn{2}{|c|}{ Multivariate analysis } \\
\hline & & & Hazard ratio $(95 \% \mathrm{CI})$ & P-value ${ }^{a}$ \\
\hline Gender, male vs. female & $93 / 25$ & 0.407 & & \\
\hline Age (years), $>70$ vs. $\leq 70$ & $58 / 60$ & 0.396 & & \\
\hline Tumor number, single vs. multiple & $75 / 43$ & $<0.001$ & $0.468(0.291-0.751)$ & 0.002 \\
\hline Maximum tumor size $(\mathrm{cm}),>4.5$ vs. $\leq 4.5$ & $59 / 59$ & 0.335 & & \\
\hline Microscopic vascular invasion, yes vs. no & $52 / 66$ & 0.024 & $0.648(0.406-1.032)$ & 0.068 \\
\hline $\operatorname{AST}(\mathrm{IU} / \mathrm{l}), \geq 40$ vs. $<40$ & $53 / 65$ & 0.035 & & \\
\hline $\operatorname{ALT}(\mathrm{IU} / \mathrm{l}), \geq 40$ vs. $<40$ & $34 / 84$ & 0.880 & & \\
\hline ALP (IU/1), $\geq 300$ vs. $<300$ & $56 / 62$ & 0.002 & $0.827(0.492-1.391)$ & 0.474 \\
\hline GGT (IU/l), $\geq 100$ vs. $<100$ & $58 / 60$ & 0.010 & $0.680(0.399-1.159)$ & 0.156 \\
\hline FIB-4 index $\geq 2.97$, yes vs. no & $60 / 58$ & 0.014 & $0.640(0.390-0.988)$ & 0.044 \\
\hline Serum albumin level (g/dl), $\geq 4.0$ vs. $<4.0$ & $74 / 44$ & 0.933 & & \\
\hline Total bilirubin $(\mathrm{mg} / \mathrm{dl}), \geq 1.0 \mathrm{vs} .<1.0$ & $23 / 95$ & 0.817 & & \\
\hline Platelet count $\left(\mathrm{x} 10^{4} / \mathrm{mm}^{3}\right), \geq 15$ vs. $<15$ & $64 / 54$ & 0.063 & & \\
\hline Prothrombin time $(\%), \geq 80$ vs. $<80^{\mathrm{b}}$ & $98 / 18$ & 0.052 & & \\
\hline Diabetes mellitus, yes vs. no & $53 / 65$ & 0.652 & & \\
\hline Body mass index $\left(\mathrm{kg} / \mathrm{m}^{2}\right), \geq 25 \mathrm{vs} .<25$ & $49 / 69$ & 0.916 & & \\
\hline $\operatorname{Serum~AFP}(\mathrm{ng} / \mathrm{ml}), \geq 40$ vs. $<40$ & $31 / 87$ & 0.116 & & \\
\hline $\mathrm{DCP}(\mathrm{mAU} / \mathrm{ml}), \geq 200$ vs. $<200^{\mathrm{c}}$ & $61 / 55$ & 0.686 & & \\
\hline
\end{tabular}

CI, confidence interval; AST, aspartate aminotransferase; ALT, alanine aminotransferase; ALP, alkaline phosphatase; GGT, $\gamma$-glutamyl transpeptidase; AFP, $\alpha$-fetoprotein; DCP, des- $\gamma$-carboxy prothrombin. ${ }^{\mathrm{a}}$ Cox proportional hazard model; ${ }^{\mathrm{b}}$ missing data, $\mathrm{n}=2$; ${ }^{\mathrm{c}} \mathrm{missing}$ data, $\mathrm{n}=2$. 
Causes of death. Thirty-five patients $(29.7 \%)$ died during the follow-up period. The causes of death were $\mathrm{HCC}$ recurrence in 24 patients, liver failure in 6 patients and miscellaneous causes in 5 patients.

HCC recurrence. In the present study, 75 patients $(63.6 \%)$ had $\mathrm{HCC}$ recurrences during the follow-up period. The patterns of $\mathrm{HCC}$ recurrence after initial treatment were: single $\mathrm{HCC}$ recurrence in the liver in 32 patients; multiple $\mathrm{HCC}$ recurrences in the liver in 28 patients; multiple $\mathrm{HCC}$ recurrences in the liver with lung metastases in three patients; multiple lung metastases in 5 patients; multiple HCC recurrences in the liver with lymph node metastases in 2 patients; multiple $\mathrm{HCC}$ recurrences in the liver with peritoneal dissemination in one patient; multiple HCC recurrences in the liver with bone metastases in one patient; multiple bone metastases in one patient; single $\mathrm{HCC}$ recurrence in the liver with duodenal invasion in one patient; and local tumor progression (recurrence in the SR site) in one patient. Treatment methods for the first HCC recurrence were: SR in 11 patients; RFA in 29 patients; TACE in 16 patients; systemic chemotherapy such as sorafenib in 7 patients; radiation therapy in 2 patients and no specific treatment in 10 patients.

In patients with a preoperative FIB-4 index $>2.97(n=60)$, HCC recurrence was found in 44 patients $(73.3 \%)$, while in patients with a preoperative FIB-4 index $<2.97$ ( $n=58)$, HCC recurrence was observed in 38 patients $(65.5 \%)$. Fifteen patients $(25.0 \%)$ had late first confirmed HCC recurrence $(>2$ years after initial SR) in patients with a preoperative FIB-4 index $>2.97$, whereas 9 patients $(15.5 \%)$ had late first confirmed HCC recurrence in patients with a preoperative FIB-4 index $<2.97$.

\section{Discussion}

To the best of our knowledge, this is the first reported study to investigate the relationship between preoperative FIB-4 index and clinical outcomes in NBNC-HCC patients treated with SR. Although the FIB-4 index has been demonstrated to be a useful noninvasive serum marker for predicting liver fibrosis in many previous studies, the effect of this marker on clinical outcomes in NBNC-HCC patients who undergo SR remains obscure (11-18). Hence, we conducted the current analyses.

In our results, the FIB-4 index yielded the highest AUROC with a level of 0.887 for cirrhosis and in the multivariate analysis, FIB-4 index was significantly associated with RFS although in terms of OS, FIB-4 index was not a significant predictor. These results revealed that the FIB-4 index has the highly discriminative ability for predicting liver cirrhosis and it could be a useful predictor for NBNC-HCC patients treated with SR. Liver biopsy, which has been considered as the 'golden standard' for defining liver fibrosis, carries some drawbacks: sampling error and inter-observer variability, which have raised questions on its value, whereas in our current analyses, we examined the effect of FIB-4 index on liver cirrhosis using non-tumor parts of extracted surgical specimens, which had sufficient amount of liver specimens for an exact assessment of extension of liver fibrosis $(13,31)$. Thus, our current data are highly reliable. One possible reason that the FIB-4 index was not a significant predictor linked to OS in the present analysis is that HCC patients with extremely poor hepatic reserve were excluded from our candidates for SR.

In our baseline characteristics, the proportion of patients with DM was $44.9 \%$ (53/118). Wang et al performed a metaanalysis including a total of 25 cohort studies to investigate the relationship between DM and HCC development and reported that DM was associated with an increased incidence of $\mathrm{HCC}(\mathrm{HR}=2.01,95 \% \mathrm{CI}=1.61-2.51)$ compared with individuals without $\mathrm{DM}$, and it was also positively associated with HCC mortality ( $\mathrm{HR}=1.56,95 \% \mathrm{CI}=1.30-1.87)$ (32). Our high proportion of diabetic patients may be associated with their results. On the other hand, the mean BMI in the present study was $24.3 \pm 3.9 \mathrm{~kg} / \mathrm{m}^{2}$ and the proportion of patients with BMI $>30 \mathrm{~kg} / \mathrm{m}^{2}$ that indicated obesity was only $7.6 \%(9 / 118)$. Obesity and its related metabolic abnormalities, including chronic inflammatory condition, have been shown to increase the risk of HCC development (33). Although the reasons for these discrepancies are unclear, other carcinogenic factors than obesity may be closely associated with NBNC-HCC development in Japanese populations. Furthermore, it is of note that the proportion of patients with F0 or F1 that indicated minimal fibrosis was $31.4 \%$ (37/118) in the present study, although advanced fibrosis was found to be a significant risk factor of HCC development in many previous reports (1-7). The carcinogenic mechanisms between NBNC-HCC and virus-related HCC may be different.

In the multivariate analysis in terms of OS, AFP was an independent predictor $(\mathrm{P}=0.026)$ and serum albumin had marginal significance $(\mathrm{P}=0.055)$. Both tumor-related factors and liver function-related factors may be essential for the management of NBNC-HCC patients treated with SR. In that sense, branched-chain amino acid therapy for background liver disease may improve clinical outcomes (34). On the other hand, as for RFS, tumor number $(\mathrm{P}=0.002)$ and FIB-4 index $(\mathrm{P}=0.044)$ were found to be independent significant predictors and the presence of microvascular invasion had marginal significance $(\mathrm{P}=0.068)$ in the multivariate analysis. Particularly in patients with these risk factors, close observation for HCC recurrence after SR is needed. Furthermore, in our results, the proportion of late HCC recurrence in patients with FIB-4 index $>2.97$ was higher than that in patients with FIB-4 index $<2.97$ (25.0 vs. 15.5\%). Several investigators have demonstrated that advanced fibrosis is related to late de novo HCC recurrence after SR in the remnant fibrotic liver $(35,36)$. Our results were consistent with their reports.

The present study included several limitations. Firstly, this is a retrospective observational study. Secondly, the sample size in the present study was relatively small for statistical analyses. Thirdly, our study cohort included only Japanese HCC patients, who in general had lower BMI than populations in Western countries $(37,38)$. Hence, caution should be exercised in interpreting our results and further larger prospective studies are necessary. However, our results demonstrated that the FIB-4 index had high discriminative ability for predicting liver cirrhosis and it could identify patients with a high risk of HCC recurrence in NBNC-HCC patients treated with SR.

In conclusion, the FIB-4 index is a useful serum marker for predicting liver cirrhosis and a useful predictor of clinical outcomes for NBNC-HCC patients who undergo SR. 


\section{Acknowledgements}

The authors would like to thank Haruko Takada for the data collection.

\section{References}

1. Osaki Y and Nishikawa H: Treatment for hepatocellular carcinoma in Japan over the last three decades: our experience and published work review. Hepatol Res: Jun 26, 2014 (Epub ahead of print). doi: $10.1111 /$ hepr.12378.

2. El-Serag HB: Epidemiology of viral hepatitis and hepatocellular carcinoma. Gastroenterology 142: 1264-1273, 2012.

3. de Lope CR, Tremosini S, Forner A, Reig $M$ and Bruix J: Management of HCC. J Hepatol 56 (Suppl 1): S75-S87, 2012

4. Kaibori M,Ishizaki M,Matsui $\mathrm{K}$ and Kwon AH:Clinicopathologic characteristics of patients with non-B non-C hepatitis virus hepatocellular carcinoma after hepatectomy. Am J Surg 204 300-307, 2012

5. Nishikawa $\mathrm{H}$ and Osaki Y: Non-B, non-C hepatocellular carcinoma (Review). Int J Oncol 43: 1333-1342, 2013.

6. Utsunomiya T and Shimada M: Molecular characteristics of noncancerous liver tissue in non-B non-C hepatocellular carcinoma Hepatol Res 41: 711-721, 2011.

7. Umemura $\mathrm{T}$ and Kiyosawa K: Epidemiology of hepatocellular carcinoma in Japan. Hepatol Res 37 (Suppl 2): S95-S100, 2007.

8. Zhou WP, Lai EC, Li AJ, Fu SY, Zhou JP, Pan ZY, Lau WY and Wu MC: A prospective, randomized, controlled trial of preoperative transarterial chemoembolization for resectable large hepatocellular carcinoma. Ann Surg 249: 195-202, 2009

9. Nishikawa H, Osaki Y, Kita R, Kimura T, Inuzuka T, Takeda H, Nakajima J, Matsuda F, Sakamoto A, Henmi S, Hatamaru K, Saito S and Nasu A: Transcatheter arterial infusion chemotherapy prior to radiofrequency thermal ablation for single hepatocellular carcinoma reduces the risk of intrahepatic distant recurrence. Int J Oncol 41: 903-909, 2012.

10. Nishikawa H, Osaki Y, Kita R, Kimura T, Ohara Y, Takeda H, Sakamoto A, Saito S, Nishijima N, Nasu A, Komekado H and Nishiguchi S: Comparison of transcatheter arterial chemoembolization and transcatheter arterial chemotherapy infusion for patients with intermediate-stage hepatocellular carcinoma Oncol Rep 31: 65-72, 2014.

11. Castera L: Invasive and non-invasive methods for the assessment of fibrosis and disease progression in chronic liver disease. Best Pract Res Clin Gastroenterol 25: 291-303, 2011.

12. Chrostek L and Panasiuk A: Liver fibrosis markers in alcoholic liver disease. World J Gastroenterol 20: 8018-8023, 2014.

13. Sumida Y, Nakajima A and Itoh Y: Limitations of liver biopsy and non-invasive diagnostic tests for the diagnosis of nonalcoholic fatty liver disease/nonalcoholic steatohepatitis. World J Gastroenterol 20: 475-485, 2014.

14. Smith JO and Sterling RK: Systematic review: non-invasive methods of fibrosis analysis in chronic hepatitis C. Aliment Pharmacol Ther 30: 557-576, 2009.

15. D'Onofrio M, Crosara S, De Robertis R, Canestrini S, Demozzi E, Gallotti A and Pozzi Mucelli R: Acoustic radiation force impulse of the liver. World J Gastroenterol 19: 4841-4849, 2013.

16. Mariappan YK, Glaser KJ and Ehman RL: Magnetic resonance elastography: a review. Clin Anat 23: 497-511, 2010

17. Yu ML, Lin SM, Lee CM, Dai CY, Chang WY, Chen SC, Lee LP, Lin ZY, Hsieh MY, Wang LY, Chuang WL and Liaw YF: A simple noninvasive index for predicting long-term outcome of chronic hepatitis $C$ after interferon-based therapy. Hepatology 44 : 1086-1097, 2006.

18. Castera L: Noninvasive methods to assess liver disease in patients with hepatitis B or C. Gastroenterology 142: 1293-1302, 2012.

19. Vallet-Pichard A, Mallet V, Nalpas B, Verkarre V, Nalpas A, Dhalluin-Venier V, Fontaine $\mathrm{H}$ and Pol S: FIB-4: an inexpensive and accurate marker of fibrosis in HCV infection. Comparison with liver biopsy and fibrotest. Hepatology 46: 32-36, 2007.

20. Angulo P, Bugianesi E, Bjornsson ES, P, Mills PR, Barrera F, Haflidadottir S, Day CP and George J: Simple noninvasive systems predict long-term outcomes of patients with nonalcoholic fatty liver disease. Gastroenterology 145: 782-789.e4, 2013.
21. Tamaki N, Kurosaki M, Matsuda S, Muraoka M, Yasui Y, Suzuki S, Hosokawa T, Ueda K, Tsuchiya K, Nakanishi H, Itakura J, Takahashi Y, Asahina Y and Izumi N: Non-invasive prediction of hepatocellular carcinoma development using serum fibrosis marker in chronic hepatitis $\mathrm{C}$ patients. J Gastroenterol: Dec 15, 2013 (Epub ahead of print).

22. Chon YE, Jung ES, Park JY, Kim do Y, Ahn SH, Han KH, Chon CY, Jung KS and Kim SU: The accuracy of noninvasive methods in predicting the development of hepatocellular carcinoma and hepatic decompensation in patients with chronic hepatitis B. J Clin Gastroenterol 46: 518-525, 2012.

23. Shen SL, Fu SJ, Chen B, Kuang M, Li SQ, Hua YP, Liang LJ, Guo P, Hao Y and Peng BG: Preoperative aspartate aminotransferase to platelet ratio is an independent prognostic factor for hepatitis B-induced hepatocellular carcinoma after hepatic resection. Ann Surg Oncol: May 22, 2014 (Epub ahead of print).

24. Hung HH, Su CW, Lai CR, Chau GY, Chan CC, Huang YH, Huo TI, Lee PC, Kao WY, Lee SD and Wu JC: Fibrosis and AST to platelet ratio index predict post-operative prognosis for solitary small hepatitis B-related hepatocellular carcinoma. Hepatol Int 4: 691-699, 2010.

25. Alberti KG and Zimmet PZ: Definition, diagnosis and classification of diabetes mellitus and its complications. Part 1: diagnosis and classification of diabetes mellitus provisional report of a WHO consultation. Diabet Med 15: 539-553, 1998.

26. Wai CT, Greenson JK, Fontana RJ, Kalbfleisch JD, Marrero JA, Conjeevaram HS and Lok AS: A simple noninvasive index can predict both significant fibrosis and cirrhosis in patients with chronic hepatitis C. Hepatology 38: 518-526, 2003.

27. Sterling RK, Lissen E, Clumeck N, Sola R, Correa MC, Montaner J, S Sulkowski M, Torriani FJ, Dieterich DT, Thomas DL, Messinger D, Nelson M; APRICOT Clinical Investigators: Development of a simple noninvasive index to predict significant fibrosis in patients with $\mathrm{HIV} / \mathrm{HCV}$ coinfection. Hepatology 43: 1317-1325, 2006.

28. Bruix J, Sherman M; Practice Guidelines Committee, American Association for the Study of Liver Diseases: Management of hepatocellular carcinoma. Hepatology 42: 1208-1236, 2005.

29. No authors listed: The general rules for the clinical and pathological study of primary liver cancer. Liver Cancer Study Group of Japan. Jpn J Surg 19: 98-129, 1989.

30. Utsunomiya T, Shimada M, Kudo M, Ichida T, Matsui O, Izumi N, Matsuyama Y, Sakamoto M, Nakashima O, Ku Y, Takayama T and Kokudo N; for the Liver Cancer Study Group of Japan: A Comparison of the surgical outcomes among patients with $\mathrm{HBV}$-positive, $\mathrm{HCV}$-positive, and non-B non-C hepatocellular carcinoma: a nationwide study of 11,950 patients. Ann Surg: Jul 28, 2014 (Epub ahead of print).

31. Nalbantoglu I and Brunt EM: Role of liver biopsy in nonalcoholic fatty liver disease. World J Gastroenterol 20: 9026-9037, 2014.

32. Wang C, Wang X, Gong G, Ben Q, Qiu W, Chen Y, Li G and Wang L: Increased risk of hepatocellular carcinoma in patients with diabetes mellitus: a systematic review and meta-analysis of cohort studies. Int J Cancer 130: 1639-1648, 2012.

33. Calle EE, Rodriguez C, Walker-Thurmond $\mathrm{K}$ and Thun MJ: Overweight, obesity, and mortality from cancer in a prospectively studied cohort of U.S. adults. N Engl J Med 348: 1625-1638, 2003.

34. Nishikawa $\mathrm{H}$ and Osaki $\mathrm{Y}$ : Clinical significance of therapy using branched-chain amino acid granules in patients with liver cirrhosis and hepatocellular carcinoma. Hepatol Res 44: 149-158, 2014.

35. Jung KS, Kim SU, Choi GH, Park JY, Park YN, Kim do Y, Ahn SH, Chon CY, Kim KS, Choi EH, Choi JS and Han KH: Prediction of recurrence after curative resection of hepatocellular carcinoma using liver stiffness measurement (FibroScan ${ }^{\circledR}$ ). Ann Surg Oncol 19: 4278-4286, 2012.

36. Imamura H, Matsuyama Y, Tanaka E, Ohkubo T, Hasegawa K, Miyagawa S, Sugawara Y, Minagawa M, Takayama T, Kawasaki S and Makuuchi M: Risk factors contributing to early and late phase intrahepatic recurrence of hepatocellular carcinoma after hepatectomy. J Hepatol 38: 200-207, 2003.

37. McCurry J: Japan battles with obesity. Lancet 369: 451-452, 2007.

38. Examination Committee of Criteria for 'Obesity Disease' in Japan; Japan Society for the Study of Obesity: New criteria for 'Obesity Disease' in Japan. Circ J 66: 987-992, 2002. 